\title{
OPTIMIZATION OF A THIN-WALLED ELEMENT GEOMETRY USING A SYSTEM INTEGRATING NEURAL NETWORKS AND FINITE ELEMENT METHOD
}

\begin{abstract}
Artificial neural networks [ANNs] are an effective method for predicting and classifying variables. This article presents the application of an integrated system based on artificial neural networks and calculations by the finite element method [FEM] for the optimization of geometry of a thin-walled element of an air structure. To ensure optimal structure, the structure's geometry was modified by creating side holes and ribs, also with holes. The main criterion of optimization was to reduce the structure's weight at the lowest possible deformation of the tested object. The numerical tests concerned a fragment of an elevator used in the "Bryza" aircraft. The tests were conducted for networks with radial basis functions [RBF] and multilayer perceptrons [MLP]. The calculations described in the paper are an attempt at testing the FEM - ANN system with respect to design optimization.

Keywords: artificial neural networks, numerical modelling, thin-walled element
\end{abstract}

\section{Motivation}

Neural networks $(\mathrm{NN})$ are an effective methods for predicting or classifying variables. There are many publications on applications of the artificial intelligence methods for the purpose of prediction [1-5]. NN are mathematical structures enabling the processing of signals by other elements due to the use of certain models which perform input operations. Nowadays we can observe a significant role played by artificial intelligence methods in predicting material parameters or investigating strength of composite materials or failure behavior analyses [6-20]. The research on stiffened, buckling-susceptible composite elements used in the aircraft industry, oriented at reducing structure weight, by the finite element method in the Abaqus program and neural networks, was conducted among others by a research team from the Department of Aerospace Science and Technology, Politecnico di Milano [21].

Given the trend for reducing weight of air structures while maintaining their strength and rigidity unchanged makes design engineers look for optimized design solutions. It can be done by using specialized programs like Tosca, but it should be noted that the geometry result is raw and requires a smoothing process. In addition to this, the optimization program does not provide information about the relationships between individual parameters describing geometry and the considered result, such as displacement or acceptable stresses. This data can be obtained using neural networks, which have been used in the present study. The neural networks are part of a complex hybrid system which uses the finite element method - obtained numerical results as input variables. It must be stressed that the authors have considerable experience in the use of numerical methods of calculation based on both artificial intelligence e.g. [2,3,22-24] and finite elements e.g. [25-28].

In all FEM application NNs can be applied to improve designing process to get better engineering solutions satisfying different conditions and requirements. In the present paper these requirements are:

- Keeping the stiffness of the element on relatively high level, expressed by maximum displacement $u_{\max }$.

- $\quad$ Reducing the weight of the element $w$.

\section{Aim of the work}

To make air structures as lightweight as possible, they are mainly made of aluminum or fibrous composites. The study was performed on a fragment of the airfoil used to control flight altitude in the aircraft (Fig. 1).

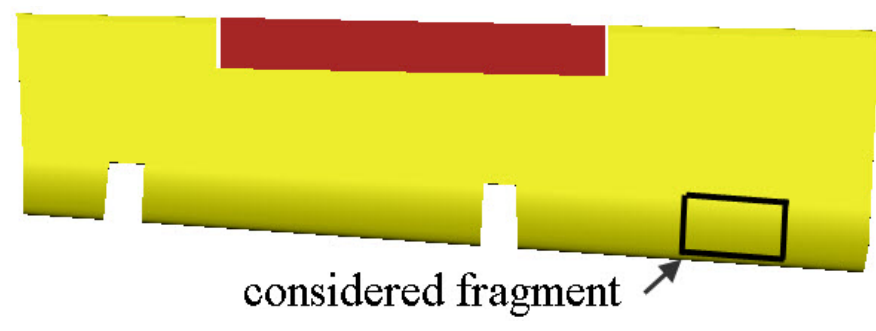

Fig. 1. Considered fragment of the aircraft wing

\footnotetext{
* LUBLIN UNIVERSITY OF TECHNOLOGY, 20-618 LUBLIN, 40 NADBYSTRZYCKA STR., POLAND

\# Corresponding author: j.gajewski@pollub.pl
} 
This fragment was idealized to cubic shape with a height of $60 \mathrm{~mm}$, a width of $165 \mathrm{~mm}$ and a length of $265 \mathrm{~mm}$, made of aluminum with a thickness of $0.8 \mathrm{~mm}$. Since it was difficult to predict the values of hole radius, rib thickness and their angle of inclination relative to the side walls, therefore we performed over 160 FEM simulations for different geometrical configurations of dimensions applied.

To ensure optimal structure, the structure's geometry was modified by creating:

- $\quad$ system of ribs, situated under different angles in relation to side of the cuboid,

- different thickness of ribs,

- set of holes inside of the ribs,

- $\quad$ set of holes inside of the side walls of the cuboid.

\section{Description of the investigated models}

The investigated model is loaded at 20 points located on two planes forming ribs in a real structure (Fig. 2). The specified loads system corresponds to the real state of loading during airplane flight in the considered box. It causes complex state of stress including bending and torsion.

The finite element mesh was built with 182956 C3D8R elements and 690 C3D6 elements. The global dimension of each element was $2 \mathrm{~mm}$, and there were 4 elements located on the thickness of each wall (Fig. 2).

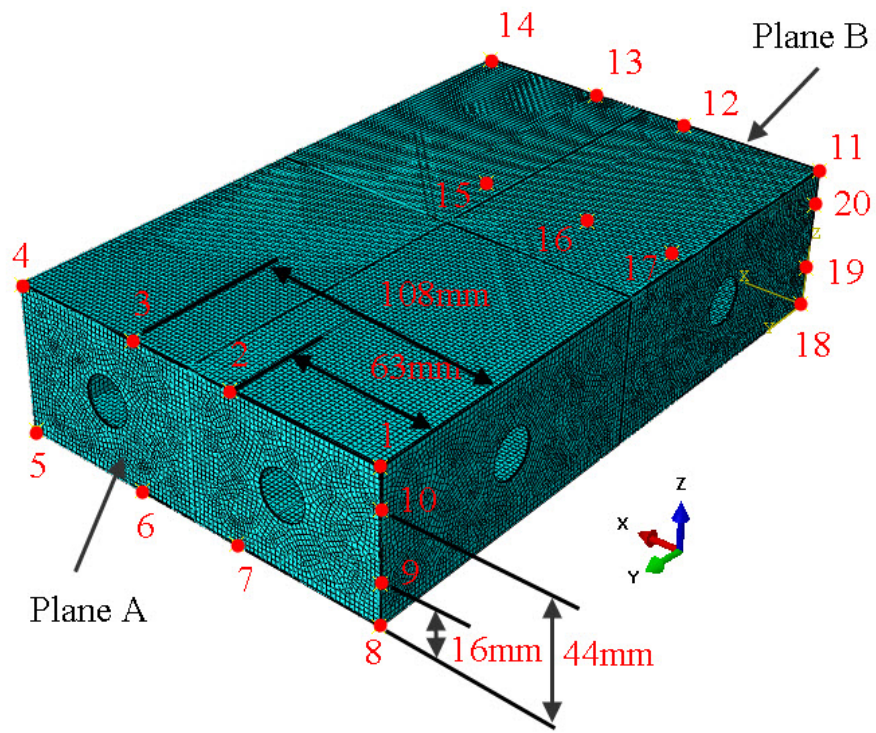

Fig. 2. 3D view of the structure with marked points of application of stresses

Besides the application of stresses, it was also important to remove relevant degrees of freedom: point $5-u_{\mathrm{y}}=u_{\mathrm{z}}=0$, point $8-u_{\mathrm{x}}=u_{\mathrm{y}}=u_{\mathrm{z}}=0$, point $18-u_{\mathrm{z}}=0$.

Table 1 lists the real stresses components of the structure loaded with in the FEM modeling. To apply the load, it was however necessary to do partitioning, so the stresses are applied in the simulation to square surfaces with the dimensions $1.2 \times 1.2 \mathrm{~mm}$.
TABLE 1

Boundary stress system conditions corresponding to the structure in Fig. 2

\begin{tabular}{|c|c|c|c|c|c|c|c|}
\hline \hline \multicolumn{6}{|c|}{ Plane A } & \multicolumn{4}{c|}{ Plane B } \\
\hline point & $\begin{array}{c}\boldsymbol{\sigma}_{\mathbf{x}} \\
{[\mathbf{M P a}]}\end{array}$ & $\begin{array}{c}\boldsymbol{\sigma}_{\mathbf{y}} \\
{[\mathbf{M P a}]}\end{array}$ & $\begin{array}{c}\boldsymbol{\sigma}_{\mathbf{z}} \\
{[\mathbf{M P a}]}\end{array}$ & point & $\begin{array}{c}\boldsymbol{\sigma}_{\mathbf{x}} \\
{[\mathbf{M P a}]}\end{array}$ & $\begin{array}{c}\boldsymbol{\sigma}_{\mathbf{y}} \\
{[\mathbf{M P a}]}\end{array}$ & $\begin{array}{c}\boldsymbol{\sigma}_{\mathbf{z}} \\
{[\mathbf{M P a}]}\end{array}$ \\
\hline 1 & 66,53 & $-182,85$ & 22,92 & 11 & $-51,32$ & 220,97 & $-52,99$ \\
\hline 2 & 83,82 & $-131,11$ & 5,56 & 12 & $-61,88$ & 140,97 & $-17,43$ \\
\hline 3 & 59,86 & $-81,11$ & $-7,92$ & 13 & $-56,18$ & 84,24 & $-0,14$ \\
\hline 4 & 43,06 & $-133,19$ & $-46,25$ & 14 & $-64,51$ & 194,65 & 67,43 \\
\hline 5 & $-38,61$ & 116,88 & $-57,15$ & 15 & 62,22 & $-183,40$ & 64,79 \\
\hline 6 & $-53,75$ & 80,07 & $-15,07$ & 16 & 59,93 & $-77,78$ & 8,13 \\
\hline 7 & $-73,06$ & 142,01 & $-6,11$ & 17 & 63,19 & $-138,54$ & $-9,79$ \\
\hline 8 & $-84,44$ & 189,24 & 73,13 & 18 & 46,60 & $-234,24$ & $-97,29$ \\
\hline 9 & 1,46 & 27,29 & 27,50 & 19 & $-2,36$ & $-34,65$ & 6,18 \\
\hline 10 & 66,53 & $-182,85$ & 22,92 & 20 & $-51,32$ & 220,97 & $-52,99$ \\
\hline
\end{tabular}

Figure 3 shows the geometrical parameters, i.e. 4 individual variables of the presented model, which are modified in the simulations. They are:

- rib thickness ranging from $0.2 \mathrm{~mm}$ to $2 \mathrm{~mm}$,

- side hole radius ranging from $2.5 \mathrm{~mm}$ to $25 \mathrm{~mm}$,

- rib hole radius ranging from $2.5 \mathrm{~mm}$ to $25 \mathrm{~mm}$,

- $\quad$ rib angle ranging from $0^{\circ}$ to $82.5^{\circ}$.

The thickness of the side walls $t$ as well as of the upper and lower skins were maintained constant at $0.8 \mathrm{~mm}$. All the above parameters were edited in the Abaqus CAE environment. After each parameter change, the FEM model was remeshed. In this calculations the Abaqus / Standard solver was used and it was a static analysis. Aerospace structures have to operate below the yield point, however in this work an elastic-plastic model with linear hardening of aluminum 2024 described by the following parameters were used: Young modulus $-\mathrm{E}=73.1 \mathrm{GPa}$, yield point $-\sigma_{\mathrm{y}}=300 \mathrm{MPa}$, rupture tensile strength $-\sigma_{\mathrm{r}}=469 \mathrm{MPa}$, and unit elongation at rupture $-\mathrm{A} 5=20 \%$. The aim of the elastic - plastic material model application was better observations the most efforted places and making corrections of geometrical parameters. It should be emphasized that in none of the considered models yield stress does not occur.

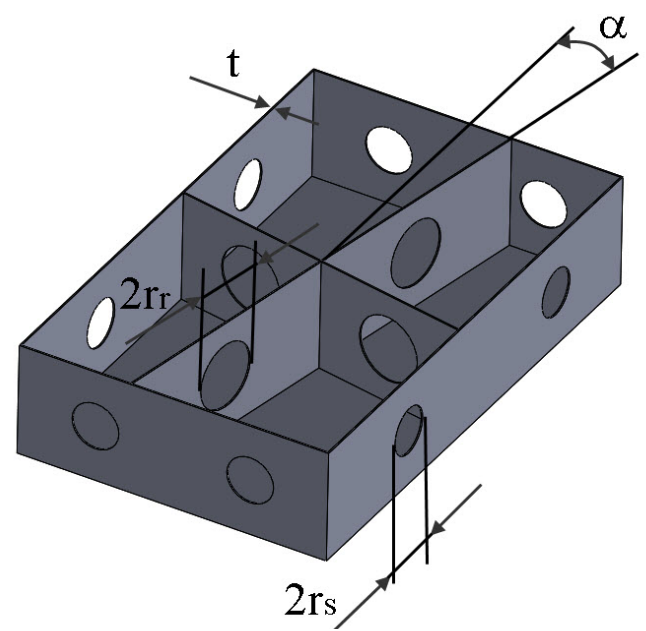

Fig. 3. Modifications of the examined geometrical parameters: rib thickness $t$, side hole radius $r_{\mathrm{s}}$, rib hole radius $r_{\mathrm{r}}$, rib angle $\alpha$ 


\section{Results of the FEM analysis}

The figures below illustrate the results for one parameter configuration, where the angle $\alpha$ is $75^{\circ}$, the rib thickness $t$ is $0.2 \mathrm{~mm}$, the rib hole radius $r_{\mathrm{r}}$ is set to $25 \mathrm{~mm}$ and the side hole radius $r_{\mathrm{s}}$ is made equal to $20 \mathrm{~mm}$. The computations were made using Abaqus Standard.

The crucial parameters measured in each case were the maximum displacement and weight, which in the discussed case were $u_{\max }=0.2323 \mathrm{~mm}$ and $w=293 \mathrm{~g}$, respectively. The distribution of the resultant displacements in the entire structure is shown in Fig. 4.

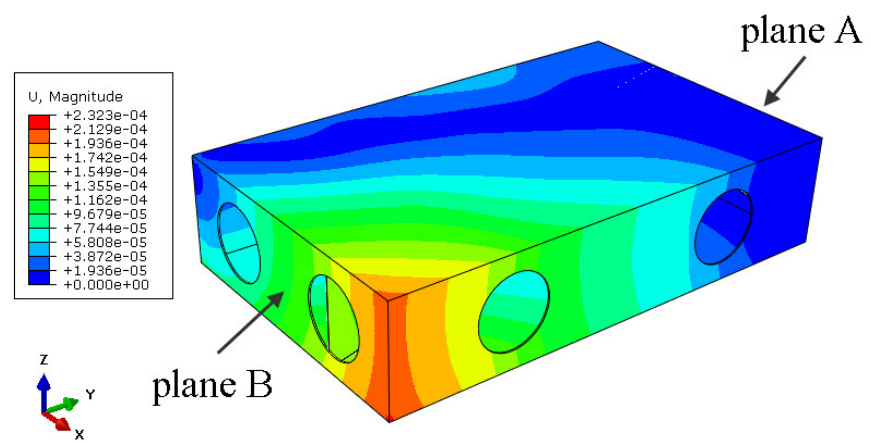

Fig. 4. Distribution of the resultant displacements and deformed geometry

The highest displacement $u_{\max }$ can be observed in the case of the corner that is located at the highest distance from the support conditions.

Table 2 shows the results for boxes with above mentioned characteristics $\left(t, \alpha, r_{\mathrm{r}}, r_{\mathrm{s}}\right)$. As the primary model, the geometry without ribs, but with holes in the side walls was assumed. For this model we get the biggest displacement $u_{\max }$. By adding the ribs, a decrease of displacement followed of about $1,07 \%$, but the weight increased by $5,3 \%$. Therefore, providing holes in the robs gives a compromise between weight $w$ increase and deflection decrease.

TABLE 2

The results for displacement and weight values

\begin{tabular}{|l|c|c|}
\hline & $\boldsymbol{u}_{\max }[\mathbf{m m}]$ & Weight $\boldsymbol{w}$ [g] \\
\hline Box with holes in side walls & 0,2335 & 283 \\
\hline $\begin{array}{l}\text { Box with holes in side walls } \\
\text { and with ribs }\end{array}$ & 0,2310 & 298 \\
\hline $\begin{array}{l}\text { Box with holes in side walls } \\
\text { and with holes in ribs }\end{array}$ & 0,2323 & 293 \\
\hline
\end{tabular}

Figure 5 shows the distribution of the reduced (Huber von Mises) stresses. Their values are below $130 \mathrm{MPa}$, so the yield point is not exceeded. The highest concentrations of the reduced stresses are located at points of load application and in accordance with the Saint-Venant principle they are decreased in cross-sections fare away from the applied loads. To avoid such situations in the future works, the loads should be applied to larger area or the submodel should be used.

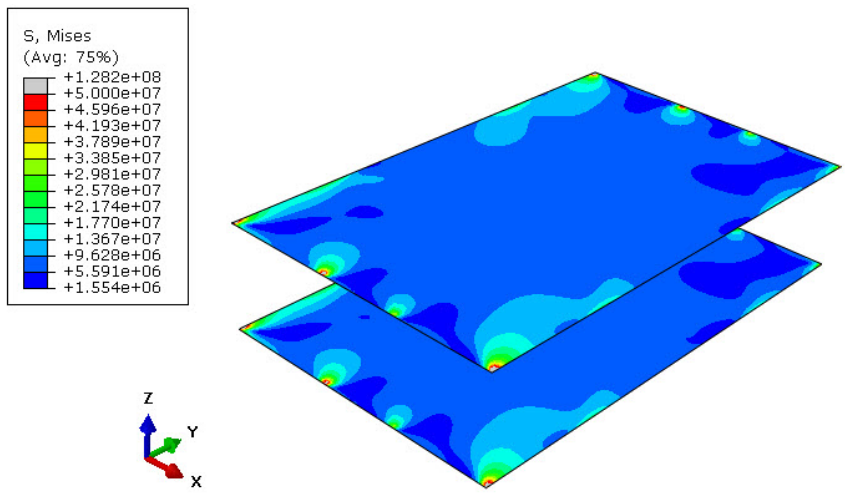

Fig. 5. Distribution of the reduced (Huber - von Mises) stresses in the top and bottom plates

A similar situation can be observed in the case of side walls shown in Fig. 6: the yield point is not exceeded and the stresses are equal to $154 \mathrm{MPa}$ (at the points of load application). The stresses reaching $40 \mathrm{MPa}$ also occur in the vicinity of holes in the longer side walls.

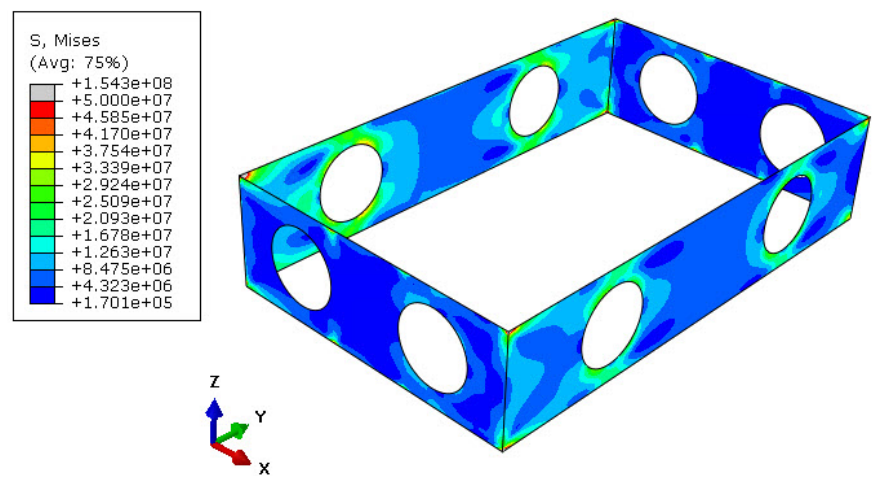

Fig. 6. Distribution of the reduced (Huber - von Mises) stresses in the side walls

The lowest values of the reduced stress concentration were observed in the inside ribs, where the maximum amounting to $16 \mathrm{MPa}$ occurs in the vicinity of the holes shown in Fig. 7.

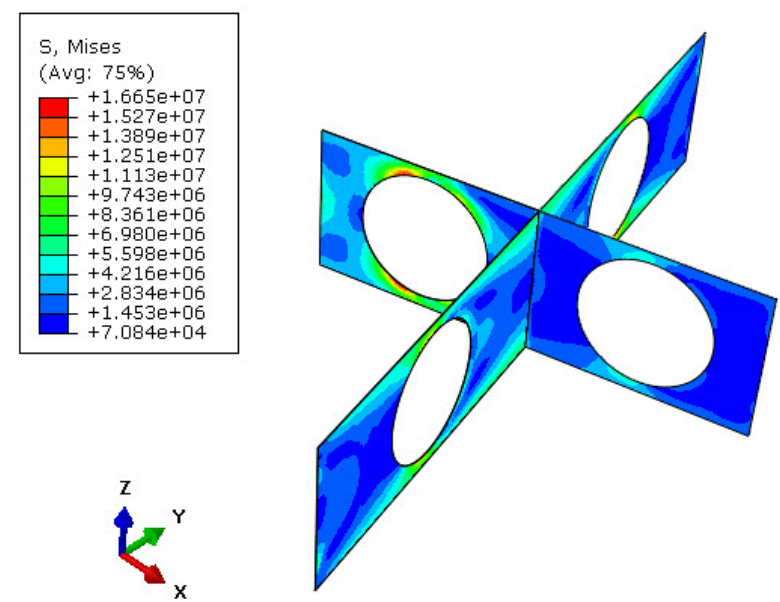

Fig. 7. Distribution of the reduced (Huber - von Mises) stresses in the ribs 


\section{Description of the neural models}

The FEM analysis enables determination of the above parameters for a single examined case, without precise information about the model's sensitivity to its individual parameters. The objective of the analyses with the application of artificial neural networks was to investigate the effect of variables on the model's stiffness and deformation $u_{\max }$ as well as weight prediction. The proposed approach enables the synergy of both methods, FEM and NN. As a result of neural network training, it will be possible to not only determine the examined model variables but also perform a sensitivity analysis of the model, which will provide a basis for optimization of the model's geometrical parameters. The literature provides information concerning the attempts at using artificial neural networks with the FEM analysis [29].

The numerical computations were run for two model variants. The first variant involved loading 4 quantitative input variables. They were: rib wall thickness, the angle of rib inclination relative to the side walls, side hole diameter and rib hole diameter. The output variable was the structure's deformation under the applied load. The second variant, the input variables included 2 quantitative input variables, i.e. side hole and rib hole diameters, as well as 2 qualitative variables, i.e. the defined rib angles and wall thicknesses.

The tests were conducted for multilayer perceptron (MLP) as these network, based on the results of previous research [2,3,23-24], are best suited for solving this particular model of regression. A schematic design of a MLP neural network is given in Fig. 8.

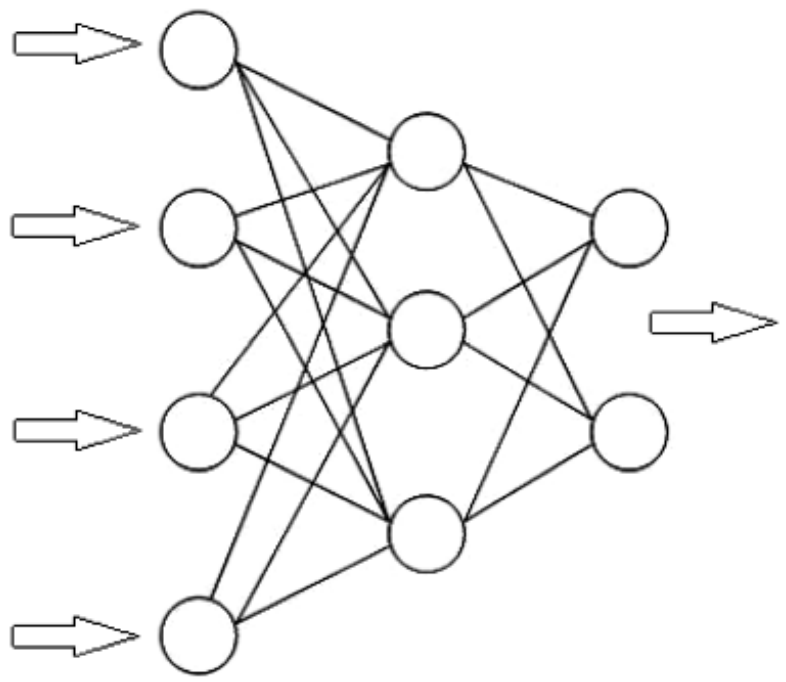

Fig. 8. Schematic diagram of an MLP neural network

The most promising models out of the examined MLP are listed in Tables 3 and 4. The employed network training method was the BFGS algorithm due to its effectiveness and insensitivity to all kinds of minimization inaccuracies. The analyses were performed for the networks with different numbers of neurons in the hidden layer.

\subsection{Analyses with 4 quantitative inputs}

The experimental data obtained from the FEM analysis were divided into 3 groups. $70 \%$ of cases were assigned to the group of training data, $15 \%$ to the validation set, and the remaining $15 \%$ to the testing set. Such a division of data enables testing the model's effectiveness using data which were not used for network training. The variables were matched with relevant sets at random. We used over 160 cases that were network input signals and contained information about the output. The creation of a network consist of obtaining a function which describes the predicted variables in the best possible way compared to the available experimental data. The following functions were used as activation functions for neurons in the hidden and output layers: linear, exponential, logistic and hyperbolic tangent.

TABLE 3

Activation functions and quality of the models

\begin{tabular}{|c|c|c|c|c|c|c|c|}
\hline No. & 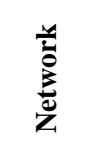 & 象总 & 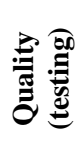 & 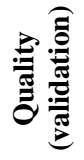 & 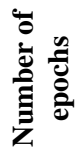 & 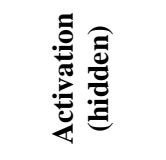 & 氖 \\
\hline 1 & $\begin{array}{l}\text { MLP } \\
4-5-1 \\
\end{array}$ & 0.94 & 0.95 & 0.91 & 22 & Logistic & Logistic \\
\hline 2 & $\begin{array}{l}\text { MLP } \\
4-3-1\end{array}$ & 0.94 & 0.94 & 0.93 & 19 & Logistic & Exponential \\
\hline 3 & $\begin{array}{c}\text { MLP } \\
4-10-1\end{array}$ & 0.98 & 0.95 & 0.93 & 61 & Exponential & Tanh \\
\hline
\end{tabular}

The specific types of the employed activation functions in both layers for the models are listed in Table 3. The training quality values listed in the table correspond to the coefficients of correlation between the real data and the numerical results.

TABLE 4

Sensitivity analysis of multilayer perceptrons

\begin{tabular}{|c|c|c|c|c|}
\hline \hline \multirow{2}{*}{ Network } & \multicolumn{4}{|c|}{ Sensitivity analysis with respect to displacement } \\
\cline { 2 - 5 } & Side holes & Rib angle & Wall thickness & Rib holes \\
\hline 1. MLP 4-5-1 & 10.2 & 1.1 & 1.0 & 0.9 \\
\hline 2. MLP 4-3-1 & 11.0 & 1.1 & 1.1 & 1.0 \\
\hline 3. MLP 4-10-1 & 32 & 4.8 & 1.9 & 1.7 \\
\hline
\end{tabular}

The values listed in Table 4 reveal the impact of a given input variable on operation of the model. The results demonstrate that the most important variable is the size of holes in the side walls of the box. This is the expected result yet the degree of significance of this parameter is surprising. The network depends on this input variable to such a great extent that this raises a concern regarding the impact of other variables on deformation prediction. This phenomenon results from the behavior of the model in FEM analysis at larger diameters of holes in the side walls, where the displacements rapidly increase due to fact of significant decrease of the cuboid stiffness. This can clearly be observed in Fig. 9. 
The results lead to a conclusion that the model's weight can be reduced by considerably increasing rib hole diameters, as this will be of much less importance for strain values than the modification of side holes. Figures 9 and 10 show forecasting

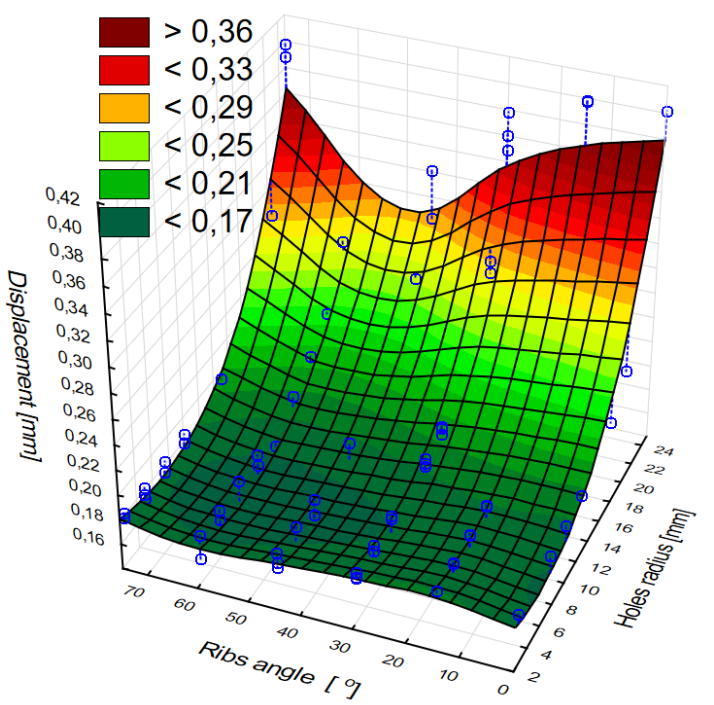

Fig. 9. Displacement $u_{\max }$ versus rib angle $\alpha$ and side hole radius $r_{\mathrm{s}}$

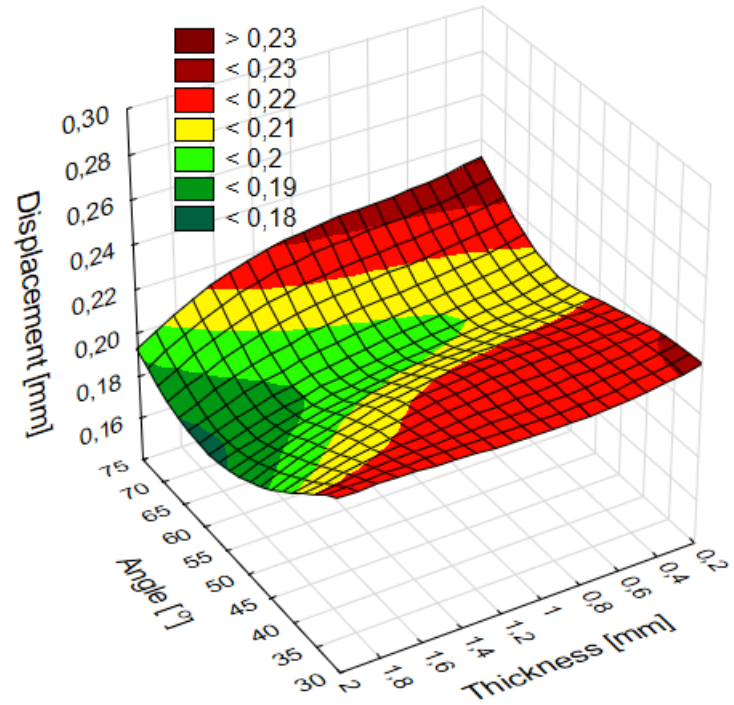

Fig. 11. Displacement $u_{\max }$ versus thickness $t$ and rib angle $\alpha$

The most interesting is the effect on the model of the angle of the ribs and the diameter of the side holes. The graphs indicate that the smallest displacement values are forecasted for the angle of the ribs about 50-55 degrees. Deformation decreases with increasing thickness $t$ of the wall and grows hyperbolically with increasing diameter of holes $2 r_{\mathrm{s}}$ in the side walls.

\subsection{Analyses with 2 quantitative and 2 qualitative inputs}

The use of this solution is limiting as regards the network versatility - the network can make predictions only for selected weight $w$ and displacement $u_{\max }$ by the neural network system as a function of rib angle $\alpha$ and side hole radius $r_{s}$. Figures 11 and 12 illustrate the response of the model to the varying thickness $t$ and rib angle $\alpha$.

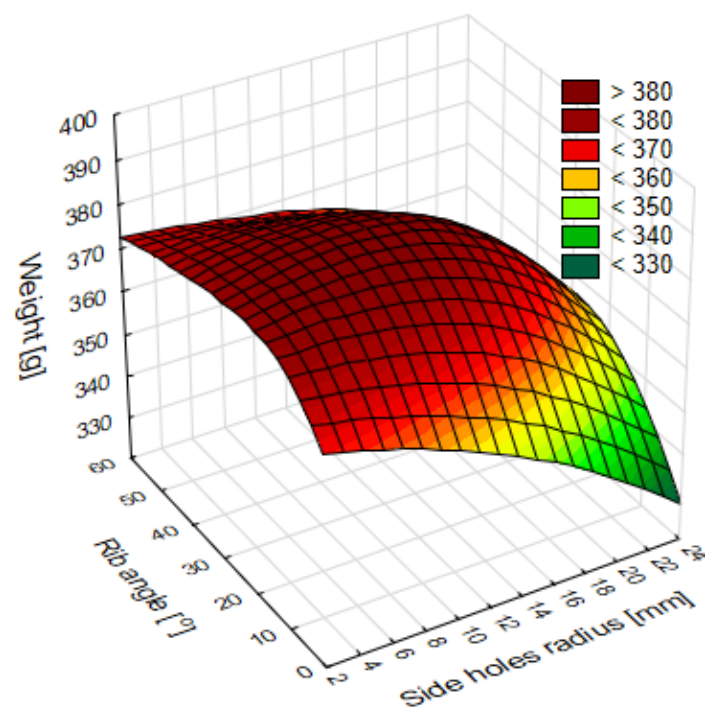

Fig. 10. Weight $w$ versus rib angle $\alpha$ and side hole radius $r_{\mathrm{s}}$

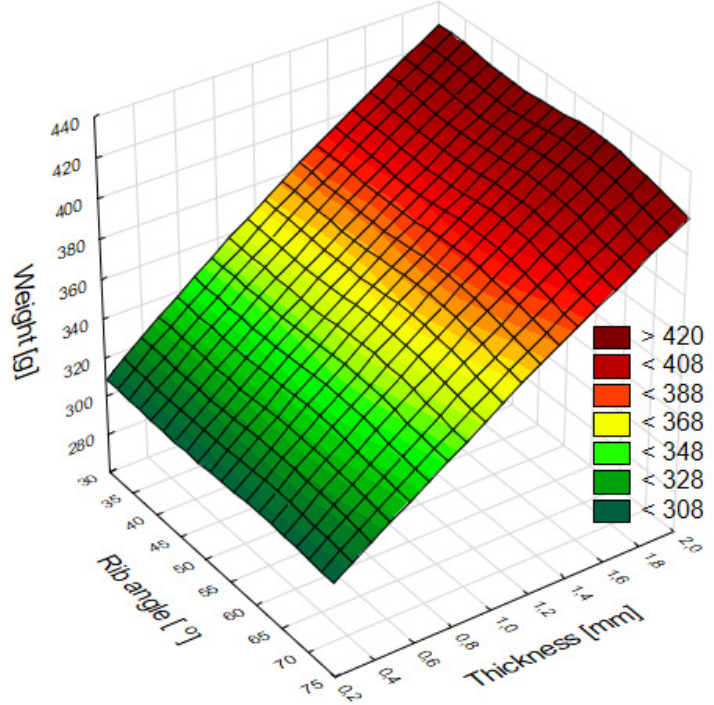

Fig. 12. Weight $w$ versus thickness $t$ and rib angle $\alpha$

groups of parameters; nonetheless, this helps to analyze better the network's sensitivity to some parameters.

The input data included the following ranges of variables: - Rib thickness $t=0.2 \mathrm{~mm} ; 0.8 \mathrm{~mm} ; 1.4 \mathrm{~mm} ; 2 \mathrm{~mm}$, - $\quad$ Rib angle $\quad \alpha=0^{\circ} ; 15^{\circ} ; 30^{\circ} ; 45^{\circ} ; 60^{\circ} ; 75^{\circ}$,

- Side hole diameter $2 r_{s}=0 \div 25 \mathrm{~mm}$,

- Rib hole diameter $2 r_{r}=0 \div 25 \mathrm{~mm}$.

We used a system of 3 networks presented in Table 5 . The network error defined as the difference between the values of the variable predicted by the model and the real variable resulting from the mean square error in the process of network training was small. Therefore, it can be concluded that the network good 
represents the tested model. What can be observed with respect to all models in this case is that the side hole radius is the most significant variable here, while the variable which has the lowest impact on the model deformation is the rib hole radius. The results of this analysis variant lead to a conclusion that rib angle is the crucial variable regarding the stiffness of the model and its maximum displacement $u_{\max }$.

TABLE 5

Sensitivity of the models (quotient)

\begin{tabular}{|c|c|c|c|c|}
\hline \multirow{2}{*}{ Network } & \multicolumn{4}{|c|}{ Sensitivity analysis (displacement) } \\
\cline { 2 - 5 } & Wall thickness & Rib angle & Side holes & Rib holes \\
\hline 1. MLP 12-14-1 & 47 & 107 & 510 & 2 \\
\hline 2. MLP 12-5-1 & 38 & 80 & 402 & 2 \\
\hline 3. MLP 12-10-1 & 68 & 118 & 476 & 2 \\
\hline
\end{tabular}

The quality of the tested models, the results of which are listed in Table 6 , similarly to that of the network with 4 quantitative input variables, is satisfactory. The listed values concern the training, validation and testing sets. The table also lists the

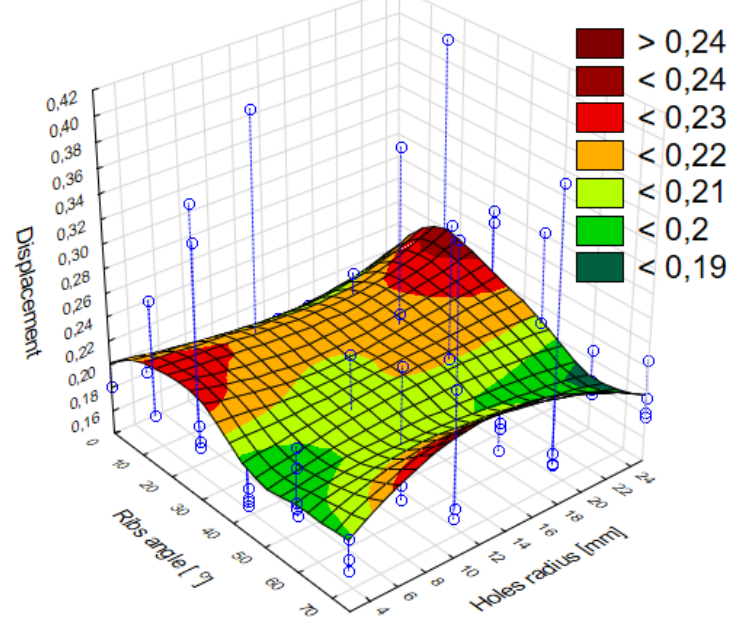

Fig. 13. Displacement $u_{\max }$ versus rib hole radius $r_{\mathrm{r}}$ and rib angle $\alpha$

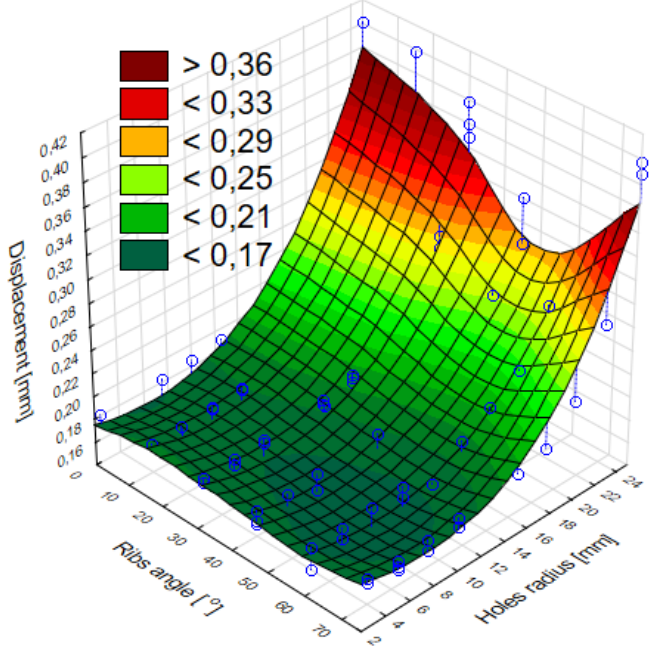

Fig. 15. Displacement $u_{\max }$ versus rib angle and side hole radius $r_{\mathrm{s}}$ number of epochs and activation functions in the hidden and output layers of individual networks.

TABLE 6

MLPs parameters

\begin{tabular}{|c|c|c|c|c|c|c|c|}
\hline$\dot{z}$ & 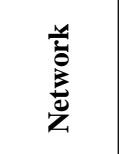 & 坣罖 & 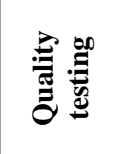 & 象: & 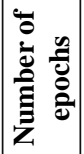 & 氧总 & 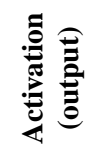 \\
\hline 1 & $\begin{array}{c}\text { MLP } \\
12-14-1\end{array}$ & 0.99887 & 0.99474 & 0.99773 & 76 & Logistic & $\begin{array}{l}\text { Expo- } \\
\text { nential }\end{array}$ \\
\hline 2 & \begin{tabular}{|l|} 
MLP \\
$12-5-1$ \\
\end{tabular} & 0.99877 & 0.99523 & 0.99821 & 161 & $\begin{array}{c}\text { Expo- } \\
\text { nential }\end{array}$ & $\begin{array}{c}\text { Expo- } \\
\text { nential }\end{array}$ \\
\hline 3 & $\begin{array}{c}\text { MLP } \\
12-10-1\end{array}$ & 0.99879 & 0.99568 & 0.99710 & 84 & Tanh & $\begin{array}{l}\text { Expo- } \\
\text { nential }\end{array}$ \\
\hline
\end{tabular}

The charts in Figs 13-16 illustrate the impact of the rib angle $\alpha$ and other input parameters on displacement $u_{\max }$ and weight $w$ of the model. The graphs indicate that the smallest displacement values are forecasted for the angle of the ribs about 50-60 degrees. The chart in Fig. 13 illustrates the relationship

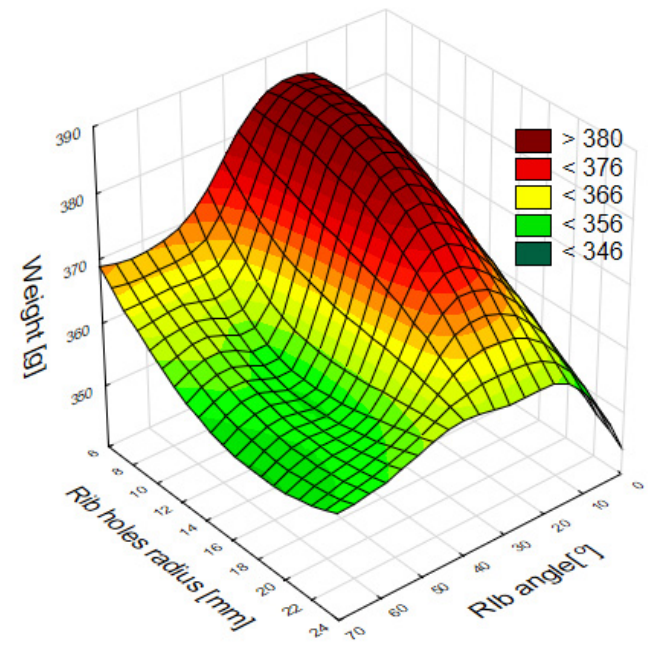

Fig. 14. Weight $w$ versus rib hole radius $r_{\mathrm{r}}$ and rib angle $\alpha$

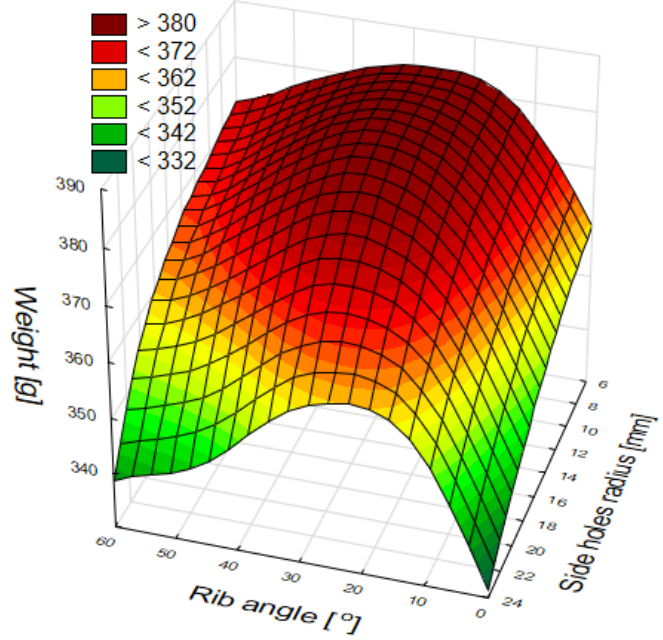

Fig. 16. Weight $w$ versus rib angle and side hole radius $r_{\mathrm{s}}$ 
between displacement vs rib hole diameter. The results can cast doubts on the network-generated approximation accuracy of the effect exerted by this particular variable. Maximum weight values can be observed for an angle of approximately 30 degrees (Fig. 14 and 16).

\section{Conclusions}

The most important conclusion from the research is the ability to use the considered methods to optimize the design process. Application of FEM data as variables to the neural network data can quickly and effectively assess the structure parameters. The proposed approach can also be used for other types of structures designed, especially composites.

The results of neural networks sensitivity analysis demonstrate that the key variable in model design regarding the structure's deformation is the diameter of holes in side walls. This is an important conclusion about considered model, because the walls are the main carrying element of the box. To reduce the element's weight, the diameters of rib holes must be increased. It is also necessary to consider increasing rib length, even at the expense of the model's weight, while at the same time decreasing the thickness of rib walls $t$ in the model.

\section{Acknowledgement}

Financial support of Structural Funds - European Regional Development Funds (ERDF) Project No: INNOLOT/I/5/NCBiR/2013; program "INNOLOT - Innovative Aviation" coordinated by the National Center for Research and Development (NCBiR - Poland); Title: "Block Structures - Mechanical joining innovations to replace conventional fasteners in aerostructures" Period: 1.12.2013-31.11.2018 is gratefully acknowledged, This work was financially supported by Ministry of Science and Higher Education within the statutory research number S/20/2016.

\section{REFERENCES}

[1] B. Wang, JH. Ma, YP. Wu. Application of artificial neural network in prediction of abrasion of rubber composites, Materials and Design 49, 802-807 (2013).

[2] J. Jonak, J. Gajewski, Identifying the cutting tool type used in excavations using neural networks, Tunn. Undergr. Space Technol. 21, 185-189, (2006).

[3] J. Jonak, J. Gajewski, Identification of ripping tool types with the use of characteristic statistical parameters of time graphs, Tunn. Undergr. Space Technol. 23, 18-24 (2008).

[4] G. Litak, J. Gajewski, A. Syta, J. Jonak, Quantitative estimation of the tool wear effects in a ripping head by recurrence plots, Journal of Theoretical and Applied Mechanics 46, 521-530 (2008).

[5] H. El Kadi. Modeling the mechanical behavior of fiber-reinforced polymeric composite materials using artificial neural networks $-\mathrm{A}$ review, Composite Structures 73, 1-23 (2006).
[6] Ch.M. Bishop, Neural Networks for Pattern Recognition. Clarendon Press, Oxford, (1996).

[7] L.H. Yam, Y.J. Yan, J.S. Jiang, Vibration-based damage detection for composite structures using wavelet transform and neural network identification, Composite Structures 60, 403-412 (2003).

[8] Z. Su, L. Ye, Lamb wave-based quantitative identification of delamination in CF/EP composite structures using artificial neural algorithm, Composite Structures 66, 627-637 (2004).

[9] Xu Y., You T., Du C.. An integrated micromechanical model and BP neural network for predicting elastic modulus of 3-D multi-phase and multi-layer braided composite, Composite Structures 122, 308-315 (2015).

[10] N.I.E. Farhana, M.S. Abdul Majid, M.P. Paulraj, E. Ahmadhilmi, M.N. Fakhzan Gibson A.G. A novel vibration based non-destructive testing for predicting glass fibre/matrix volume fraction in composites using a neural Network model, Composite Structures 144, 96-107 (2016).

[11] A. De Fenza, A. Sorrentino, P. Vitiello, Application of Artificial Neural Networks and Probability Ellipse methods for damage detection using Lamb waves, Composite Structures 133, 390-403 (2015).

[12] R. Perera, A. Arteaga, A. De Diego, Artificial intelligence techniques for prediction of the capacity of RC beams strengthened in shear with external FRP reinforcement, Composite Structures 92, 1169-1175 (2010).

[13] H. Man, G. Prusty, Neural network modelling for damage behaviour of composites using full-field strain measurements, Composite Structures 93, 383-391 (2011).

[14] M. Abouhamze, M. Shakeri. Multi-objective stacking sequence optimization of laminated cylindrical panels using a genetic algorithm and neural networks, Composite Structures 81, 253-263 (2007).

[15] H. Naderpour, A. Kheyroddin, G. Ghodrati Amiri, Prediction of FRP-confined compressive strength of concrete Rusing artificial neural networks, Composite Structures 92, 2817-2829 (2010).

[16] Kai Guan, Lina Jia, Xiaojun Chen, Junfei Weng, Fei Ding, Hu Zhang. Improvement of fracture toughness of directionally solidified $\mathrm{Nb}$-silicide in situ composites using artificial neural network, Materials Science \& Engineering A 605, 65-72 (2014).

[17] Cao Jiuwen, Lin Zhiping, Huang Guang-bin. Composite function wavelet neural networks with extreme learning machine, Neurocomputing 73, 1405-1416 (2010).

[18] P. Ramasamy, S. Sampathkumar, Prediction of impact damage tolerance of drop impacted WGFRP composite by artificial neural network using acoustic emission parameters, Composites: Part B 60, 457-462 (2014).

[19] I. Mansouri, O. Kisi, Prediction of debonding strength for masonry elements retrofitted with FRP composites using neuro fuzzy and neural network approaches, Composites: Part B 70, 247-255 (2015).

[20] M. Amirjan, H. Khorsand, M. Hossein Siadati, R Eslami Farsani, Artificial Neural Network prediction of $\mathrm{Cu}-\mathrm{Al} 2 \mathrm{O} 3$ composite properties prepared by powder metallurgy method, J. Mater. Res. Technol. 2, 351-355 (2013). 
[21] S. Fu X, Ricci, C. Bisagni Minimum-weight design for three dimensional woven composite stiffened panels using neural networks and genetic algorithms, Composite Structures 134, 708-715 (2015).

[22] J. Gajewski , J. Podgorski, J. Jonak, Z. Szkudlarek, Numerical simulation of brittle rock loosening during mining process, Computational Materials Science 43, 115-118 (2008).

[23] J. Gajewski, L. Jedliński, J. Jonak, Classification of wear level of mining tools with the use of fuzzy neural network, Tunn Undergr Space Technol. 35, 30-36 (2013).

[24] J. Gajewski, J. Jonak, Towards the identification of worn picks on cutterdrumsbased on torque and power signals using Artificial Neural Networks. Tunn. Undergr. Space Technol. 26, 22-28 (2011).

[25] T. Sadowski, J. Golewski, The influence of quantity and distribution of cooling channels of turbine elements on level of stresses in the protective layer TBC and the efficiency of cooling, Computational Materials Science 52, 293-297 (2012).

[26] T. Sadowski, J. Golewski, Detection and numerical analysis of the most efforted places in turbine blades under real working conditions, Computational Materials Science 64, 285-288 (2012).

[27] T. Sadowski, J. Golewski, Multidisciplinary analysis of the operational temperature increase of turbine blades in combustion engines by application of the ceramic thermal barrier coatings (TBC), Computational Materials Science 50, 1326-1335 (2011).

[28] J Bieniaś, H. Dębski, B. Surowska, T. Sadowski, Analysis of microstructure damage in carbon/epoxy composites using FEM, Computational Materials Science 64, 168-172 (2012).

[29] J. Gajewski, T. Sadowski, Sensitivity analysis of crack propagation in pavement bituminous layered structures using a hybrid system integrating Artificial Neural Networks and Finite Element Method, Computational Materials Science 82, 114-117 (2014). 